\title{
Positive Psychologists on Positive Psychology: Michael Steger
}

\author{
Interview by \\ Aaron Jarden
}

\begin{abstract}
Michael Steger is an assistant professor in the Counseling Psychology and Applied Social Psychology programs at Colorado State University and has been involved in the field of positive psychology for the last ten years. Mike's research focuses on the foundations and benefits of living a meaningful life, and he is well known for developing the widely used Meaning in Life Questionnaire.
\end{abstract}

\section{What prompted you to become interested in positive psychology?}

My interest came first from the topic of 'meaning'. It was sort of an idealistic thing. I considered myself to be a little counter-cultural, a little hopeful that I would be able to find some tool that could help me shake people up or give people motivation to find a different way of living, a little bit more in accordance with collectivist values. So I stumbled on 'meaning'. It was only after I started reading about meaning that I ran into a buddy of mine who said, "Hey, here's a good conference for you, you should check it out", and I think it was the second Positive Psychology Summit, which was the first one I went to.

\section{How long would you say you've been interested in positive psychology?}

Well as soon as I found out about it, that is, since about 2002. So for just about ten years now I've been interested in positive psychology.

Over the course of your career in positive psychology so far, what would you say are some of the key events?

The major events for me were early influences by two different people. One was my advisor, at the University of Minnesota, where the tradition is measurement. She invited me to evaluate the measurement of meaning and I did, using all the graduate school tools for ripping things to shreds - and it wasn't good. I didn't like any of the measures and I pointed out flaws that other people had identified in them as well. So she said, "Here at Minnesota, we fix it, so that's your next project". So I developed the Meaning of Life Questionnaire. The next big thing was that Martin Seligman put it on the Authentic Happiness web page and that got it out there. For me as a grad student at the time, it made me feel like I was actually doing legitimate science in this area and made it feel important in that way.

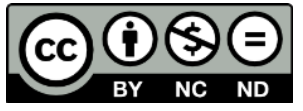

Copyright belongs to the author(s) www.internationaljournalofwellbeing.org 


\section{In general terms what would you say are some of the distinctive features of positive psychology?}

For me the most defining feature is that it's science driven. It captures an appealing array of aspirations that people have and experiences that people desire, and find important and helpful. But what really sets us apart from other people looking at those same things has to be the science.

\section{What do you think is one of the big questions that positive psychology is seeking to answer?}

How can we have people experience the best that they can experience? And the question that we are neglecting is 'what does that mean?' - What is the best that people can experience? And that's not actually probably an empirical question. So you have all these battles of values and perspectives that take place; and so that, to me, is the interesting subtext: that we're all pushing for the same thing but we view it, oftentimes, in very drastically different ways.

\section{What would you say were the field of positive psychology's greatest accomplishments to date?}

It's really been amazing. It has created an interdisciplinary space that, originally, was only interdisciplinary within psychology, with a few economists and one philosopher. It's grown and it's captured both practical, applied and research attention across many disciplines around this now widely accepted notion that we can learn how to be better off. That has been remarkable. I don't think that anyone saw it coming right before and on the heels of Sept $11^{\text {th }}$ in this country [the United States].

\section{If you were in charge of positive psychology now, what is one thing you'd change?}

It seems that a lot of people in positive psychology are heavily linked into revenue streams and that's OK, I don't have a problem with that. But in the early days of positive psychology there was a concerted effort to get graduate students to these conferences and allow them to meet these mentors and to fire them up. A lot of the graduate students at those earlier conferences were given $\$ 500$ scholarships and didn't have to pay the fee to come. And then you'd be right next to these people you'd been reading and marveling at. There used to be a top to bottom approach to really fuel new and exciting ideas. Positive psychology has in some ways gotten to the place where the top stays at the top, the middle stays at the middle, etc., and a lot of people seem to be pulling resources out of positive psychology and into their own areas of interest, rather than returning it back into the field to continue feeding the growth. I don't know if that's a fair criticism or not, but it feels a lot more expensive and isolated to be a positive psychology graduate student now than it used to be.

\section{What's one aspiration you have for the field of positive psychology?}

One of my aspirations for the field has already been answered in some ways. I really hoped when I started getting excited about this and trying to participate in my own way, that we'd catch the eye and the ear of the people who have influence to actually impact on lives. In one way that has happened, with those people who are trying to go from a seven to a nine on the 10 point scale-instead of the people who are trying to go from the negative two to the positive three-the people that are not clinically suffering. But for those people who are socially disadvantaged, economically disadvantaged-outside of the people that can pay a lot of money 
to be treated or coached-I think that is really where a lot of exciting things will happen in the future.

\section{Is there anything that you think particularly stands out in that space?}

Based on some recent experiences in South Africa, there are a lot of indigenous cultural models of people who are incredibly disadvantaged in comparison to the wealthy nations in the world; yet there's some sort of positive and inspiring homeostasis that they've reached amidst all the deprivation, all the brutality, all the lack of opportunity. What would be really cool would be continuing to grow out from the Western, affluent origins of positive psychology to join with the growing indigenous knowledge of psychologists around the world working within their own people, with what really works in their own places. I think we'll have lots of really neat ideas and inspiring stories to reach out and broaden the impact of positive psychology around the world. In psychology as a whole, we're getting good at developing Western models for positive change, and then showing that they can be readily adapted for elsewhere. So, the stuff we do seems to work, but are we missing things that could be grown from other traditions? What things are created and work elsewhere that we could all benefit from? What are the other 'mindfullnesses' out there?

\section{Which particular professional groups (aside from psychologists) are becoming more interested in positive psychology or perhaps your work on meaning?}

Those interested in the work I do on meaning are career coaches and career psychologists, particularly doing work related to women's issues in careers. Almost all the interviews I do are from women's magazines and are related to mid-career women, and career-balancing women, and also looking at the emerging workforce and those wanting to go to the next level in their careers. But I think that the world of work has been the biggest outside consumer of positive psychology. It seems like there are dozens of people who are doing industrial consulting and looking at happiness in the workplace leading to more productive, happy, workers. Education will be a really cool place - they're interested, they just need more support. Those interested in more general meaning in life issues often appear to be in medical fields, particularly oncology and palliative care.

\section{Who do you look up to most in the field of positive psychology?}

That's a great question. I really like Laura King, her work bounces around a lot of different methods, a lot of different perspectives. She's done some really inspirational work on meaning in life with a graduate student named Josh Hicks. But I also think that just as a person, she is super approachable, super generative. I think Bob Emmons, as a person and as a scholar, has been really giving of what he does. The same is definitely true about Ed Diener. The list of people whose work I admire is very long, going back to the inspirational folks like [Victor] Frankl, and those that have done really solid, foundational work like Carol Ryff. These people have some 'meaning' angle. I like that because it shows that you can step outside of your research area and attack a question.

\section{If you could start learning about positive psychology again, what would you do differently?}

I probably wouldn't want to start with measurement. One of the things that happens when you start developing a measure is that it's great because it gives you a focal point and a tool to begin to do what you want to do; and if the measurement in the area had been better, then I wouldn't 
have done it. But it also, in a sense, locks you into that tool, and so a lot of my early research was around 'how do I validate this thing in this group?', and 'how do I validate it in this group?'. And I did a lot of things that were right because they were fun, collaborating with people who had different perspectives. The biggest thing that we can do in this field is collaborate, especially by doing different things. Starting again, I'd avoid measurement and I'd really try to challenge myself more to meet folks who are using methods that I'd never heard of.

\section{Who do you think are some of the emerging or unknown researchers in the field of positive psychology? Who do you look at and think 'their research is cutting edge and cool'?}

I really like Matt Vesser's work. He's been looking at the role of meaning in Terror Management Theory and that's been something that is really cool and that there is a place for, but I never did the work myself. He's published in JPSP [Journal of Personality and Social Psychology], so he's not really super unknown or anything like that. What is astonishing is that as the access to international researchers has grown, I've realized that there is amazing research going on all over the place that we don't hear about because we just keep reading the same journals. There are some really cool people, including Lazslo Brassai, who's doing some really cool work with adolescents in Romania; there are people like Linda Theron doing great work in South Africa on AIDS orphans and there are other just amazing pieces that don't get circulated, except for in places like the International Journal of Wellbeing of course.

\section{What do you think positive psychology could learn from the field of psychology as a whole?}

I have two pet peeves about positive psychology that are also true about the field of Psychology as a whole. They are closely related. The first is losing your grasp of what it means to be a scientific discipline where your job is not just to defend your position, but it's also to attack your position. It's to really pressure what you think is right in a brave fashion. That doesn't seem to happen a lot of the time. I think a lot of people get excited about what they're doing and they love their initial research findings and they want to see their baby live and succeed. In positive psychology though, that stuff gets applied and becomes apocryphal immediately. People somewhere are going to turn it into a book or an intervention and say it's the truth. That's really dangerous if we're not out there making sure that we are really putting pressure on our assumptions. The other thing is that forgetting what it means to be a science discipline leads to a lack of consistency in definitions of constructs and the creation of new constructs. Everyone is mixing and matching terms and inserting their values into the definitions of constructs, and that really needs to be scrutinized. It confuses the science. One example is that people seem to want to define 'purpose' as having an altruistic aim to it. That is being offered as a definition of 'purpose', and it is difficult for folks to learn that that is just one type of purpose - and you might like it best, but that doesn't mean that it's the only kind. People have asshole purposes too. We just need to figure out how to be objective about these things.

\section{What area of positive psychology do you think is the most difficult area for people to grasp and learn?}

The central area of positive psychology is the most difficult to grasp. What are we studying? What is happiness? Do we want happiness? What are we trying to learn? What is our ultimate dependent variable? I think that is hard to express to people without being a little inaccurate. 


\section{What is the first book you would recommend to someone new to positive psychology?}

My first thought is Stumbling on Happiness by Dan Gilbert, although I don't really agree with all its assumptions. It's great to start with a little bit of a skeptical eye. A fun book to read that I think is also challenging is Todd Kashdan's book Curiosity. And in terms of how we can try to be as scientific and rigorous as possible, even in a popular book while still offering practical suggestions that people might be able to use, is Sonja's [Lyubomirsky] The How of Happiness, which is very good. She's pretty honest about what we know and where we're speculating, which I admire. So there are three good books.

\section{What's the most cutting-edge book you've read personally in the last couple of years that stands out?}

I teach abnormal psychology, and I'm writing an abnormal psychology textbook at the moment, and so I'm reading a lot of the psychopathology literature. That challenges my perspective on positive psychology because I've been convinced that there really is a gap in perspectives. I originally thought it was all part of a continuum, which I think is true. But we haven't addressed the continuum. So if you look at the treatments for psychopathology, a lot of them really do fall short of going beyond simply getting rid of bad things. So that's helped me to figure out what are the things that are scalable that can bridge the gap between helping people eliminate problems, which we know how to do really well, and giving people the tools to set out some aspirations and to help to achieve them.

\section{How does someone go about getting more meaning in life?}

The easiest way to not have meaning in life is to really try to focus on having more meaning itself. Meaning comes from doing, not just thinking. I think that the main thing is to have selfunderstanding and an appreciation of your true strengths and limitations. I wouldn't say that just learning your strengths is good enough, you need a true and honest appraisal of who you are and an honest encounter with life in the moment. That should be used to help people to develop a purpose, an overall life aim or mission-maybe more than one, and sometimes they compete. But really just engage in that and in life and in those things that match your values. And from time to time check in with the question 'Are you doing the things that matter to you?'. Make sure you catch yourself once in a while doing something that matters to you and appreciate that you have that gift and the ability to do that. So it's a little bit of that reciprocal acting and being aware of what we're doing.

\section{Is there anything else that you'd like to comment on that I haven't asked about that you think would be useful to someone picking up a book on positive psychology who doesn't know anything about positive psychology?}

If someone really wants to have a research career in positive psychology, I think that the main thing is to read old stuff. A lot of what we're talking about is old. This year is the first year that I've heard people at a positive psychology conference talk about Maslow very much, even though that book was published quite a while ago. So there are great ideas out there, there are great models being used outside of positive psychology. The most important thing for a researcher to do is to read outside of positive psychology, because we are really still just studying people. For practitioners, the most important thing to understand is that some prudence is necessary because the things that we are seeing work in these correlational studies or daily diary studies, or even in internally valid experiments, aren't the same things that might 
work with clients. The creativity that coaches, and therapists, and clinicians can have is awesome, but there is a responsibility with using research to do practice that means that you can't guarantee anything about that: so maybe giving researchers a break for not always knowing what works might be helpful.

\section{Author}

Aaron Jarden

Open Polytechnic of New Zealand

aaron.jarden@openpolytechnic.ac.nz 